\title{
Effect of the Brugada syndrome mutation A39V on calmodulin regulation of Cav1.2 channels
}

\author{
Brett A Simms, Ivana Assis Souza and Gerald W Zamponi*
}

\begin{abstract}
Background: The L-type calcium channel Cav1.2 is important for brain and heart function. The ubiquitous calcium sensing protein calmodulin (CaM) regulates calcium dependent gating of Cav1.2 channels by reducing calcium influx, a process known as calcium-dependent inactivation (CDI). Dissecting the calcium-dependence of CaM in this process has benefited greatly from the use of mutant CaM molecules which are unable to bind calcium to their low affinity (N-lobe) and high affinity (C-lobe) binding sites. Unlike CDI, it is unknown whether CaM can modulate the activation gating of Cav1.2 channels.

Results: We examined a Cav1.2 point mutant in the N-terminus region of the channel (A39V) that has been previously linked to Brugada syndrome. Using mutant CaM constructs in which the $\mathrm{N}$ - and/or C-lobe calcium binding sites were ablated, we were able to show that this Brugada syndrome mutation disrupts N-lobe CDI of the channel. In the course of these experiments, we discovered that all mutant CaM molecules were able to alter the kinetics of channel activation even in the absence of calcium for WT-Cav1.2, but not A39V-Cav1.2 channels. Moreover, CaM mutants differentially shifted the voltage-dependence of activation for WT and A39V-Cav1.2 channels to hyperpolarized potentials. Our data therefore suggest that structural changes in CaM that arise directly from site directed mutagenesis of calcium binding domains alter activation gating of Cav1.2 channels independently of their effects on calcium binding, and that the $\mathrm{N}$-terminus of the channel contributes to this CaM dependent process.
\end{abstract}

Conclusions: Our data indicate that caution must be exercised when interpreting the effects of CaM mutants on ion channel gating.

Keywords: Calcium channel, Calmodulin mutant, CDI, N-terminus, Brugada, Activation, Cav1.2, L-type, IQ, Channelopathy, Voltage, Gating, CACNA1C

\section{Background}

Voltage-gated calcium channels (VGCCs) are important for modulating excitability, development and gene transcription in neurons [1] while dysfunction of these channels results in a host of neurological illnesses [2]. Conditional knockout of CACNA1C from murine cortex demonstrates that Cav1.2 has a central role in emotional learning, specifically fear conditioning and empathy [3,4]. In the heart Cav1.2 channels are essential for cardiac contraction [5-7], which is best demonstrated by its embryonic lethal knockout [8]. Also, many mutations in CACNA1C have been linked to Brugada syndrome, a cardiac disorder that is characterized by ventricular arrhythmia [9-11].

\footnotetext{
*Correspondence: Zamponi@ucalgary.ca

Department of Physiology and Pharmacology, Hotchkiss Brain Institute, University of Calgary, 3330 Hospital Dr. NW, Calgary T2N 4N1, Canada
}

Altered trafficking of VGCCs to the cell membrane or aberrant function once at the cell surface are the most common molecular deficits underling disease [12]. Too little calcium conductance reduces neuronal excitability and gene transcription, while too much calcium entry is cytotoxic [13]. Excessive calcium influx through wild type Cav1.2 (WT-Cav1.2) channels is limited by the ubiquitous calcium sensing protein calmodulin $(\mathrm{CaM})$, which promotes calcium-dependent inactivation (CDI) [14-16]. Deciphering calcium/calmodulin $\left(\mathrm{Ca}^{2+} / \mathrm{CaM}\right)$ dependent gating of various ion channels [17-20], including the complexities of Cav1.2 CDI [21-25] and trafficking [26], has benefited greatly from the use of $\mathrm{CaM}$ molecules with mutated lowaffinity (N-lobe), or high affinity (C-lobe) calcium binding sites. Each lobe of CaM has two EF-hand motifs which when mutated $\left(\mathrm{CaM}_{12}\right.$ is the N-lobe mutant and $\mathrm{CaM}_{34}$ is the C-lobe mutant) prevent the binding of calcium. CaM 
mutants unable to bind calcium have different structural properties $[27,28]$ from those of wild type CaM molecules [29-32], suggesting that these conformational changes might affect channel gating independently of their ability, or inability to bind calcium.

Years of work with CaM mutants has shown that L-type calcium channels have multiple N-terminal $[22,23,33]$ and C-terminal [24,34-37] CaM binding sites which functionally regulate global and local CDI, respectively. While investigating effects on global CDI for a Cav1.2 N-terminal point mutant (A39V) linked to Brugada syndrome $[9,38]$ we observed that $\mathrm{CaM}_{\mathrm{WT}}$ differentially affected the kinetics and voltage-dependence of activation for Cav1.2 when compared to CaM lobe mutants. We also show that these effects occur in the absence of calcium and that they can be modulated by the $\mathrm{N}$-terminal A39V mutation, indicating that the $\mathrm{N}$-terminus of the channel can be involved in CaM-dependent modulation of Cav1.2 activation.

\section{Results}

The Brugada syndrome mutant A39V disrupts N-lobe CDI of Cav1.2 channels but not CaM binding to the channel $\mathrm{N}$-terminus

We have shown in previous work that the Cav1.2 point mutant A39V linked to Brugada syndrome, does not elicit a trafficking defect in the neuronal isoform of the channel or major effects on voltage-dependent activation and inactivation [38]. Recently Dick and colleagues [22] and our group [23] have shown that the N-terminus of L-type calcium channels participates in a type of CDI which occurs when intracellular levels of calcium elevate globally - it is therefore termed global CDI. Global CDI of Cav1.2 channels relies on the N-lobe of CaM, which has a much lower affinity for calcium than the high affinity $\mathrm{C}$-lobe. In order to study global CDI of Cav1.2 channels the C-lobe of CaM must be rendered non-functional (i.e. $\mathrm{CaM}_{34}$ ) and intracellular calcium buffering made permissive for the $\mathrm{N}$-lobe of $\mathrm{CaM}$ to bind calcium (0.5 EGTA). We coexpressed Cav $\beta 2 \mathrm{a}$ and Cav $\alpha 2 \delta 1$ subunits in our structure/function analysis of A39V-Cav1.2 because this combination of auxiliary subunits is regularly used to isolate CDI $[15,22,23,39,40]$ due to the fact that Cav $\beta 2$ a slows VDI [41-43] unlike Cav $\beta 1 b$ [14].

Because of the documented role of the Cav1.2 Nterminus in CDI, we tested whether the Brugada syndrome mutant A39Vmay affect this process. This was done by overexpressing $\mathrm{CaM}_{34}$ and buffering intracellular calcium with $0.5 \mathrm{mM}$ EGTA. Figure 1A shows that WT-Cav1.2 channels show little voltage-dependent inactivation (VDI) in barium (black trace) but significant N-lobe CDI upon exposure to calcium (red trace), in agreement with our previous work [23]. A $+10 \mathrm{mV}$ test depolarization was used for comparison in Figure 1 because this test potential corresponds to the peak of the IV curve in $20 \mathrm{mM}$ external barium. Quantification of the amount of N-lobe CDI is reflected in the $f_{300}$ value (i.e. the fraction of channels which are inactivated after $300 \mathrm{~ms}$ ) at $+10 \mathrm{mV}$, which equals $0.18 \pm 0.03(n=14)$ for WT-Cav1.2 and $\mathrm{CaM}_{34}$. Figure 1B shows that A39V-Cav1.2 channels have significantly reduced N-lobe CDI at $+10 \mathrm{mV}\left(\mathrm{f}_{300}=0.09 \pm 0.02\right.$, $\mathrm{n}=13$, \# $\mathrm{p} \leq 0.04$ by student's $t$-test) with $\mathrm{CaM}_{34}$ compared to WT-Cav1.2 channels under the same conditions. To facilitate comparison the WT-Cav1.2 calcium trace is shown in grey in Figure 1B. The inset bar graph in Figure 1 shows that in addition to $+10 \mathrm{mV}, \mathrm{A} 39 \mathrm{~V}-\mathrm{Cav} 1.2$ shows significantly less CDI than WT-Cav1.2 at -10 and $0 \mathrm{mV}$ ( $\mathrm{p} \leq 0.05$ by student's $t$-test). A similar trend was seen +20 and $+30 \mathrm{mV}$, but did not reach statistical significance ( $\mathrm{p}=0.28$ and $\mathrm{p}=0.26$ by student's $t$-test, respectively), presumably because there is an increasing contribution of VDI at these potentials. Repeating the experiment with $10 \mathrm{mM}$ BAPTA intracellularly to significantly increase calcium buffering verified that both WT-Cav1.2 $\left(f_{300}=-0.06 \pm 0.16, n=9\right)$ (Figure 1C) and A39V-Cav1.2 $\left(f_{300}=0.06 \pm 0.06, n=11\right)$ (Figure 1D) channels were indeed undergoing $\mathrm{N}$-lobe $\mathrm{CDI}$ at $+10 \mathrm{mV}$, which is also supported by the flattened red traces in Figures $1 \mathrm{C} / \mathrm{D}$.

We next tested whether A39V-Cav1.2 channels exhibited augmented $\mathrm{C}$-lobe CDI by expressing the channels with $\mathrm{CaM}_{12}$. Figure 2A shows that WT-Cav1.2 channels show substantial C-lobe CDI in the presence of calcium $\left(f_{300}=0.34 \pm 0.08, n=9\right)$ which agrees with the literature $[22,44]$. Figure $2 \mathrm{~B}$ shows also that A39V-Cav1.2 also exhibits considerable C-lobe CDI $\left(f_{300}=0.28 \pm 0.06, n=9\right)$ which is not statistically different from WT-Cav1.2 channels. Overall, our data reveal a reduction in N-lobe CDI for A39V-Cav1.2, which implies a gain of function effect of this mutation. This is unexpected as Brugada syndrome is considered a loss-of-function disorder in the context of Cav1.2 channels $[9,45]$.

As N-lobe CDI was affected in the A39V mutant, we tested whether this was due to altered binding of CaM to the Cav1.2 N-terminus. We used CaM sepharose pulldowns to test whether CaM could differentially bind to fusion proteins of the distal $\mathrm{N}$-terminus (methionine 1 to proline 101) of the channel. Figure 3A shows that both $\mathrm{N}_{1-\mathrm{EX}}$ and A39V-N $\mathrm{N}_{1-\mathrm{EX}}$ GFP fusion proteins bound readily to $\mathrm{CaM}$ sepharose in $0.5 \mathrm{mM}$ calcium. This binding was completely removed with $5 \mathrm{mM}$ EGTA washes (Figure 3B). The smaller $\mathrm{N}_{1}$-GFP fusion protein (methonine 1 to lysine 63) did not bind CaM and agrees with our previous findings [23]. Altogether, these biochemical measurements show that A39V does not change the binding of $\mathrm{CaM}$ to the distal portion of the $\mathrm{N}$-terminus. It is therefore unlikely that differential $\mathrm{CaM}$ binding explains the changes in N-lobe CDI observed for A39V-Cav1.2 channels. 


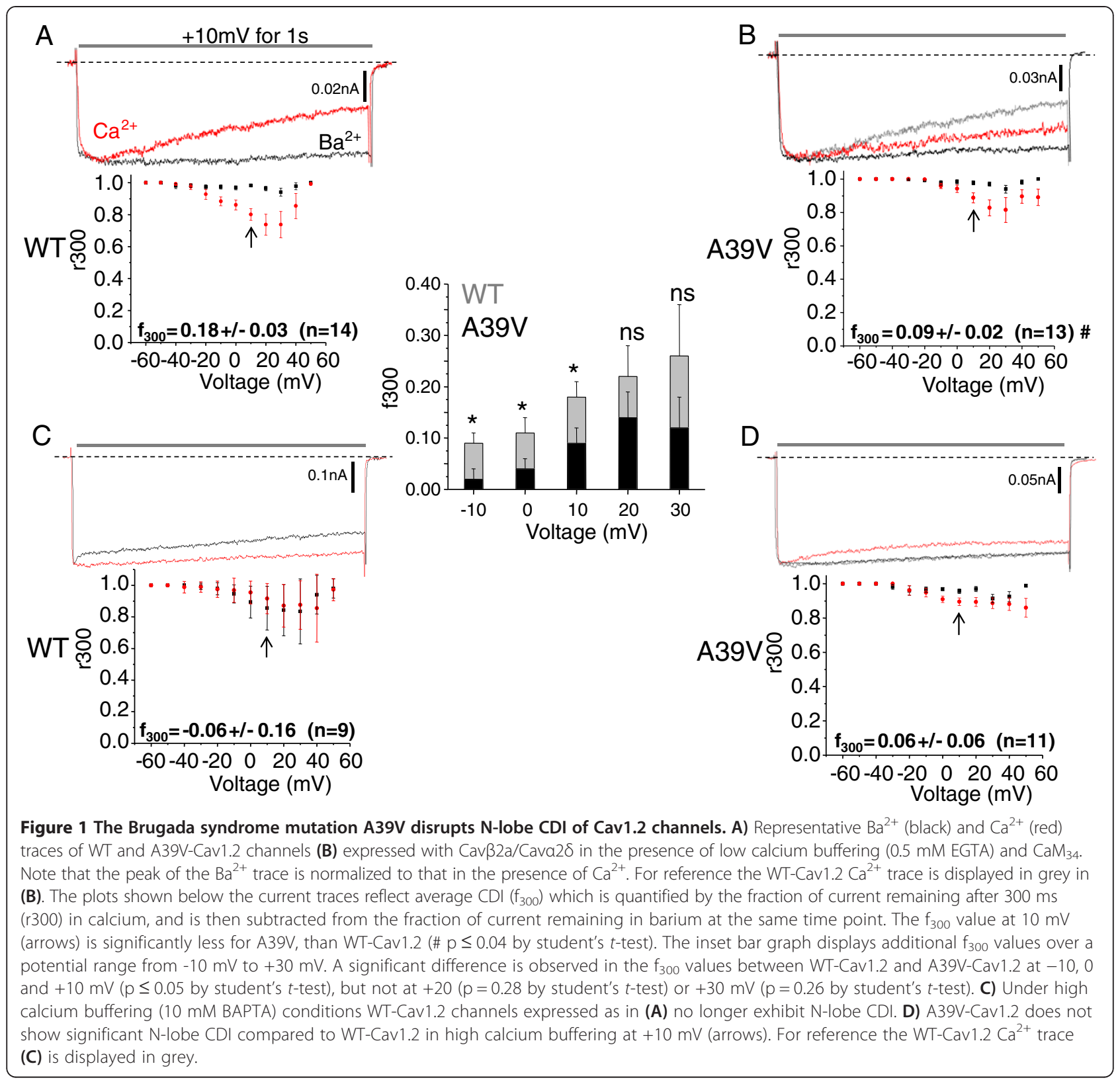

CaM mutants differentially affect the voltage-dependence and kinetics of activation for A39V and WT-Cav1.2 channels During the course of our experiments, we noticed that CaM lobe mutants affected the voltage-dependence of activation of Cav1.2 channels when bathed in extracellular barium solution. Figure 4A displays current-voltage (IV) relationships for WT-Cav1.2 channels expressed with Cav $\beta 2 \mathrm{a} / \mathrm{Cav} \alpha 2 \delta$ and either $\mathrm{CaM}_{\mathrm{WT}}$, or one of $\mathrm{CaM}_{12}$, $\mathrm{CaM}_{34}$, or $\mathrm{CaM}_{1234}$. WT-Cav1.2 channels expressed with $\mathrm{CaM}_{\mathrm{WT}}$ display a right-shifted IV relationship compared to all CaM mutants. Figure 4B displays the IV relationship for A39V-Cav1.2 under the same conditions, but in this instance, only the $\mathrm{CaM}_{12}$ condition shows an appreciable leftward shift relative to $\mathrm{CaM}_{\mathrm{WT}}$. The bar graph in Figure 4C displays the Va for WT-Cav1.2 channels and reveals that all CaM mutants show a hyperpolarizing shift in the voltage-dependence of activation relative to the $\mathrm{CaM}_{\mathrm{WT}}$ condition ( $\mathrm{p} \leq 0.05$ by one-way ANOVA). For A39V-Cav1.2 only $\mathrm{CaM}_{12}$ shows a hyperpolarizing shift in Va compared to $\mathrm{CaM}_{\mathrm{WT}}(\mathrm{p} \leq 0.05$, one-way ANOVA) (Figure 4D). Altogether, these data indicate that alterations in $\mathrm{CaM}$ structure due to the functional elimination of either the $\mathrm{N}$ - or C-lobe EF hand motifs produce direct effects on Cav1.2 channel gating. These effects are 

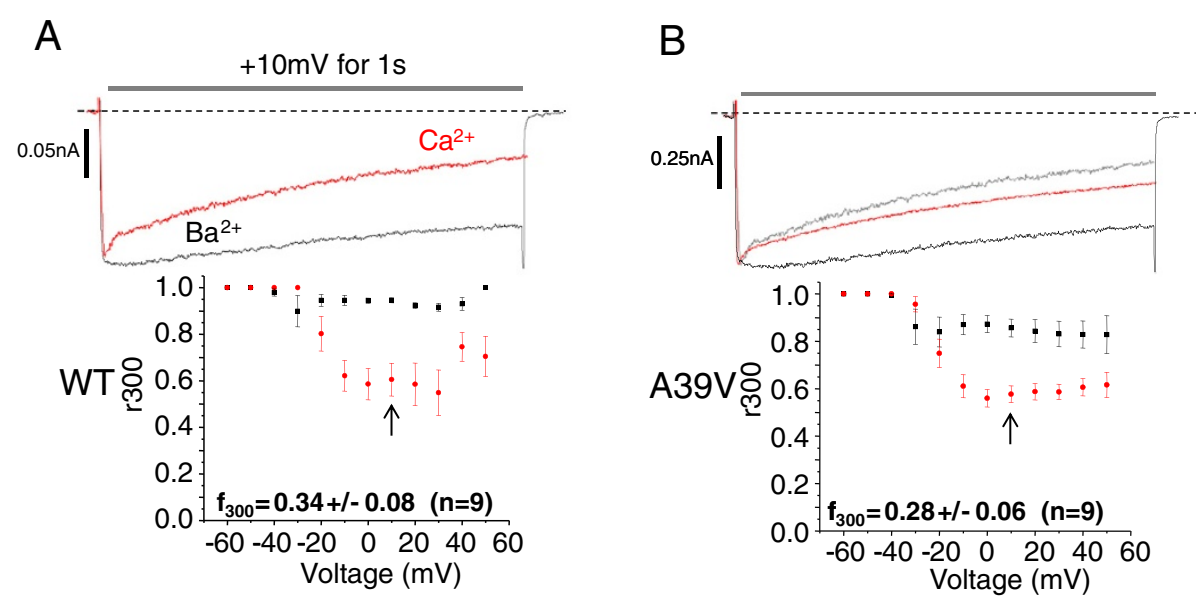

Figure 2 The Brugada syndrome mutation A39V does not affect C-lobe CDI of Cav1.2 channels. A) Representative $\mathrm{Ba}^{2+}(\mathrm{black})$ and $\mathrm{Ca}{ }^{2+}$ (red) traces of WT-Cav1.2 channels expressed with Cav $32 a / C a v a 2 \delta$ and $C_{a M}{ }_{12}$ in the presence of high calcium buffering (10 mM BAPTA). Note that the peak of the $\mathrm{Ba}^{2+}$ trace is normalized to that in the presence of $\mathrm{Ca}^{2+}$ and that average $\mathrm{CDI}\left(\mathrm{f}_{300}\right)$ of WT-Cav1.2 is displayed below in the graph. B) A39V-Cav1.2 channels expressed with Cavß2a/Cava2 $\delta$ and $\mathrm{CaM}_{12}$ in the presence of high calcium buffering (10 mM BAPTA). Inset graphs show average $C D I\left(f_{300}\right)$ which is not statistically different $(p \leq 0.55$ by student's $t$-test) between the two channel types.

present in the absence of calcium and can be modulated by the $\mathrm{N}$-terminus of the channel as the A39V-Cav1.2 data indicate.

We next examined whether the kinetics of Cav1.2 activation was affected by $\mathrm{CaM}$ mutants. Figure $5 \mathrm{~A}$ shows that WT-Cav1.2 channels recorded with Cav $\beta 2 \mathrm{a} / \mathrm{Cav} \alpha 2 \delta$ and $\mathrm{CaM}_{\mathrm{WT}}$ reach peak current amplitude much more slowly than all CaM mutants at $10 \mathrm{mV}(\mathrm{p} \leq 0.05$ by oneway ANOVA), and slower than $\mathrm{CaM}_{34}$ and $\mathrm{CaM}_{1234}$ at 0 , 20 and $30 \mathrm{mV}$ ( $\mathrm{p} \leq 0.05$ by one-way ANOVA). These data indicate that mutating the C-lobe of CaM causes WTCav1.2 channels to open much quicker than they would otherwise at physiological depolarizations. Throughout our analysis we used a single exponential equation to fit the rapid rising phase of channel activation. In rare occasions, ( 1 cell out of 9 at $+10 \mathrm{mV}$, for WT-Cav1.2), a second slower activation component was observed, but only in conditions with WT channels and $\mathrm{CaM}_{\mathrm{WT}}$. We focused on our analysis only on the fast activation time constant.

\section{Pulldown: CaM $\quad$ B
IB: GFP}

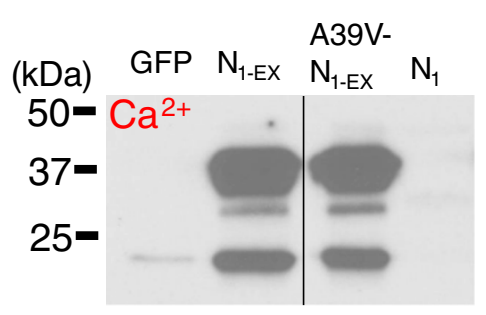

Pulldown: CaM

IB: GFP

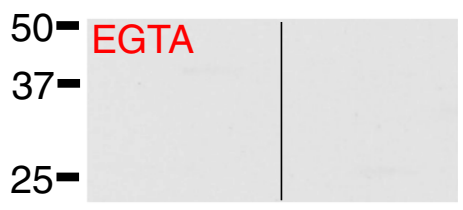

\section{IB: GFP}

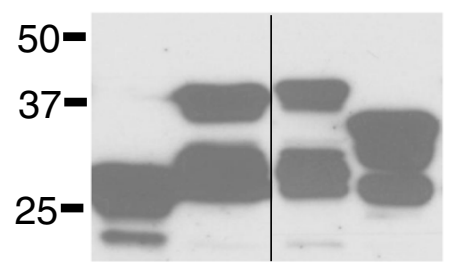

Figure 3 The Brugada mutation A39V does not alter $\mathbf{N}$-terminal binding to CaM. A) CaM sepharose pull-down experiments of $\mathrm{N}_{1-\mathrm{EX}}$, A39V-N $\mathrm{N}_{1-\mathrm{EX}}$ and $\mathrm{N}_{1}$ GFP fusion proteins in $0.5 \mathrm{mM} \mathrm{Ca}^{2+}$, or $5 \mathrm{mM}$ EGTA (B) run on SDS-PAGE with corresponding lysates (C) and blotted for GFP. Black lines mark where the gel picture was cut and irrelevant samples removed. These experiments were performed twice each. 


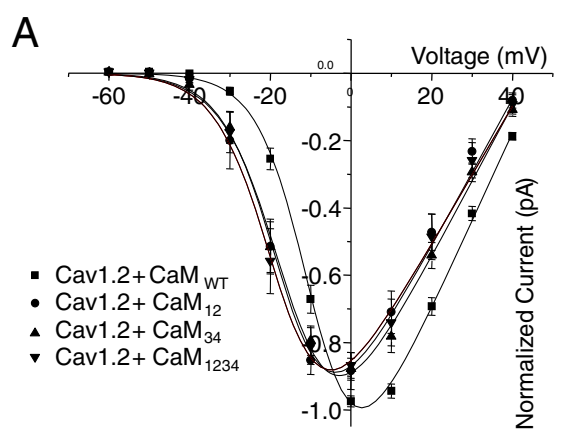

C

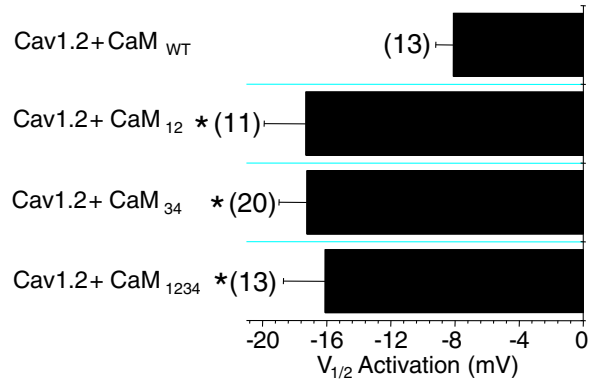

B

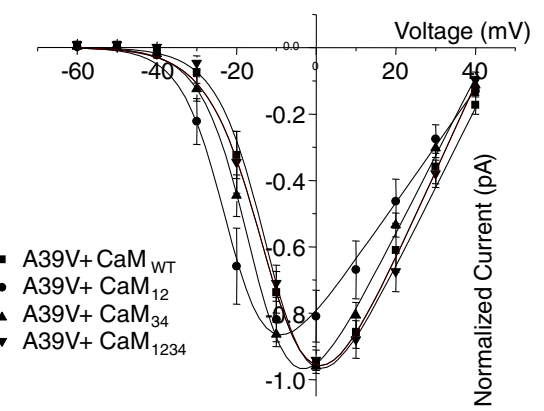

D

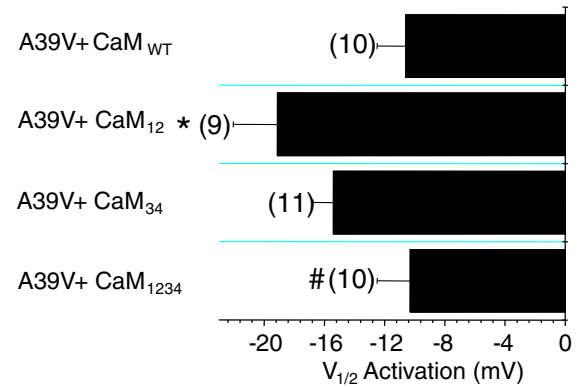

Figure 4 CaM lobe mutants differentially shift the voltage dependence of activation for WT and A39V-Cav1.2 channels. A) Current voltage relationships for WT-Cav1.2 channels expressed transiently in tsA-201 cells with Cav $\beta 2 a / C a v a 2 \delta$ and recorded in barium with one of four CaM conditions: $\mathrm{CaM}_{\mathrm{w}}, \mathrm{CaM}_{12}, \mathrm{CaM}_{34}$, or $\mathrm{CaM}_{1234}$. All experiments were recorded with high calcium buffering intracellularly (10 mM BAPTA). B) Current-voltage relationships for A39V-Cav1.2 channels expressed as in (A) with one of four CaM conditions: CaM $\mathbf{W T}_{1}, \mathrm{CaM}_{12}, \mathrm{CaM}_{34}, \mathrm{or}_{\mathrm{C}} \mathrm{CaM}_{1234}$. C) A bar graph displaying the half activation potentials for Cav1.2 channels recorded in barium. WT-Cav1.2 channels recorded with any CaM mutant have a significant leftward shift in the voltage-dependence of activation in barium compared to CaMwT ( ${ }^{*} p \leq 0.05$ by one-way ANOVA). D) A bar graph displaying the voltage dependence of activation for A39V-Cav1.2 channels recorded in barium. A39V-Cav1.2 channels recorded with CaM M $_{12}$ have a significant leftward shift in the voltage-dependence of activation in barium compared to $\mathrm{CaM}_{\mathrm{WT}}{ }^{*} \mathrm{p} \leq 0.05$ by one-way ANOVA), and CaM1234 (\# $\mathrm{p} \leq 0.05$ by one-way ANOVA).

As with the voltage-dependence of activation data, A39V-Cav1.2 channels behave differently from wild type channels with regards to their kinetics of activation in the presence of CaM mutants (Figure 5B). Specifically, at depolarized potentials A39V-Cav1.2 channels have similar kinetics of activation in the presence of wild type or mutant CaMs ( $\mathrm{p} \geq 0.05$ by one-way ANOVA). This is also illustrated in the form of whole cell current traces depicted in Figures $5 \mathrm{C}$ and D at a test depolarization of $+10 \mathrm{mV}$.

Altogether, our results reveal a previously unrecognized functional effect of CaM lobe mutants on Cav1.2 channel activation that can involve the $\mathrm{N}$-terminus of the channel.

\section{Discussion}

We have identified a novel effect of the pathophysiological mutation (A39V) through its reduction of N-lobe CDI of Cav1.2. Furthermore, our data reveal that mutant CaM molecules change activation gating for Cav1.2 channels even in the absence of calcium.

The observation that the $\mathrm{A} 39 \mathrm{~V}$ mutation reduced N-lobe CDI of Cav1.2 is surprising because Brugada syndrome is thought to involve a loss-of-function of these channels $[9,45]$, rather than the gain of function observed here. It is important to note that the cDNA construct used in our studies corresponds to the neuronal form of the channel, and it is possible that the observed gain of function is specific to neuronal channels. Importantly, A39V is only thirteen residues away from a key amino acid residue that has been implicated in N-lobe CDI (W52). Indeed, Dick and colleagues [22] suggested that during N-lobe $\mathrm{CDI}$, CaM leaves a C-terminal anchoring site upon calcium elevation to then interact directly with the $\mathrm{N}$-terminal residue W52, which in turn promotes CDI. Our recent work has expanded this idea so that CaM binds W52 and a second more proximal residue $\mathrm{C} 106$, which then transduces the CDI signal into domain I of the channel, promoting closure. The observation that A39V does not affect CaM binding to the N-terminus of Cav1.2 (Figure 3) suggests that this residue may somehow be allosterically coupled to the CDI process. This could perhaps occur by partial immobilization of the N-terminus of Cav1.2, or by promoting additional intramolecular interactions within the N-terminus, or channel regions. For example, the $\mathrm{N}$-terminus of Cav2.2 channels is capable of binding both the intracellular I-II linker and C-terminus [46]. As hydrophobic residues are often the anchor points for 
A

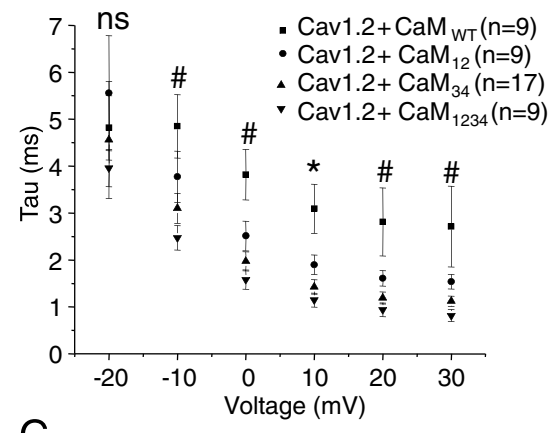

C

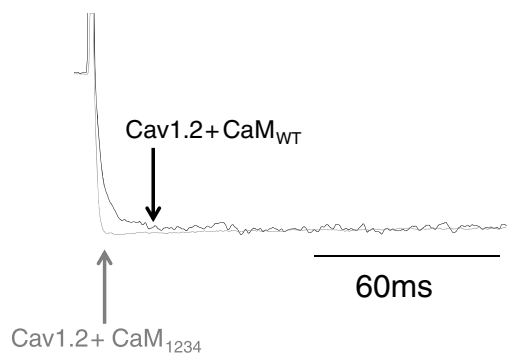

B
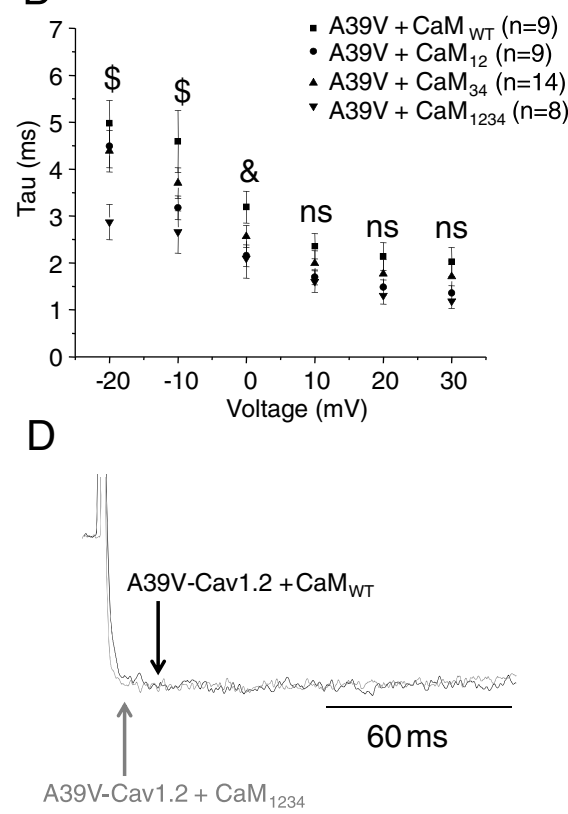

Figure 5 Calmodulin lobe mutants differentially affect the kinetics of activation for WT and A39V-Cav1.2 channels in the absence of calcium. A) Plot illustrating the time to maximum activation (Tau) at various voltages for WT-Cav1.2 channels expressed transiently in ts A-201 cells with Cavß2a/Cava2 $\delta$ and recorded in barium with one of $\mathrm{CaM}_{\mathrm{WT}}, \mathrm{CaM}_{12}, \mathrm{CaM}_{34}$ or $\mathrm{CaM}_{1234}$ and with $10 \mathrm{mM}$ BAPTA intracellular. Voltages for which all mutant CaMs differ significantly from the CaMwT condition ( ${ }^{*} \mathrm{p} \leq 0.05$ by one-way ANOVA), and where CaM $\mathrm{M}_{34}$ and $\mathrm{CaM}_{1234}$ differ from $\mathrm{CaM}_{W T}$ condition (\# $\mathrm{p} \leq 0.05$ by one-way ANOVA). B) Plot for the kinetics of activation of A39V-Cav1.2 channels expressed as in (A). Voltages for which $\mathrm{CaM}_{1234}$ differs significantly from the $\mathrm{CaM}_{W T}$ condition ( $\$ p \leq 0.05$ by one-way ANOVA), and where $\mathrm{CaM}_{12}$ and $\mathrm{CaM}_{1234}$ differ from CaM $\mathrm{MT}_{\mathrm{WT}}$ condition ( $\& p \leq 0.05$ by one-way ANOVA). C) Sample traces of WT-Cav1.2 channels expressed with CaM $\mathrm{M}_{\mathrm{WT}}$ and $\mathrm{CaM}_{1234}$ at $10 \mathrm{mV}$. Note that the $\mathrm{CaM}_{1234}$ trace has been normalized to that of $\mathrm{CaM}_{W T}$ and that the arrows denote peak of activation for WT-Cav1.2 with either CaMWT (black) or $\mathrm{CaM}_{1234}$ (grey). D) Sample traces of A39V-Cav1.2 channels expressed with CaMwt and $\mathrm{CaM}_{1234}$ at $10 \mathrm{mV}$. Note that the CaM 1234 trace has been normalized to that of $\mathrm{CaM}_{\mathrm{WT}}$ and that the arrows denote peak of activation for A39V-Cav1.2 with either CaM $\mathrm{WT}_{\text {(black) or CaM }}$ (b34 $_{\text {(grey). }}$

protein-protein interactions, it is possible that the $\mathrm{A} 39 \mathrm{~V}$ mutation may create a potential hydrophobic anchor.

How CaM molecules that are deficient in their ability to bind calcium affect Cav1.2 activation is particularly interesting. It is known that $\mathrm{CaM}_{\mathrm{WT}}$ is capable of many conformations, most of which are calcium sensitive [29-32]. Conversely, $\mathrm{CaM}_{1234}$ (and potentially $\mathrm{CaM}_{12}$ and $\mathrm{CaM}_{34}$ ) display a different set of basic conformations $[27,28]$ that may differ from calcium-free $\mathrm{CaM}_{\mathrm{WT}}$. It is thus possible that the voltage-dependence and kinetics of Cav1.2 activation may be exquisitely sensitive to subtle changes in $\mathrm{CaM}$ structure. Figure 5 shows that the kinetics of Cav1.2 activation is altered by mutant CaMs. The immediacy of this kinetic change suggests that CaMs which participate in this process must be pre-bound to the channel. Because all of our experiments were performed in barium and with $10 \mathrm{mM}$ BAPTA to buffer intracellular calcium, it is very unlikely that calcium has any role whatsoever in this effect. There is substantial evidence in the literature that in the absence of calcium CaM is tethered, or anchored to the C-terminus of VGCCs, specifically to the IQ domain $[14,15]$ and upstream PCI region [24]. Cav1.2 channels also have an EF-hand motif in the proximal C-terminus which has been proposed to be involved in the transduction of CDI signals in the holo channel [39,47-49]. Immediately downstream of the EF-hand region is the PCI region which anchors the N-lobe of $\mathrm{CaM}$ in the absence of calcium [24]. The EF-hand of Cav1.2 has also been shown to modulate the voltage-dependence of activation with changing magnesium concentrations, a process which occurs also in the absence of calcium [50,51]. We propose that the inherent conformational differences of $\mathrm{CaM}$ mutants leverage the EF-hand region differently than $\mathrm{CaM}_{\mathrm{WT}}$ and perhaps in a manner analogous to magnesium occupancy. The observation that this effect was abrogated in the A39V mutant may then indicate that this region may be functionally coupled to the $\mathrm{C}$-terminus/ CaM complex.

However, irrespective of the underlying molecular mechanisms, our data reveal that widely used CaM mutant constructs may exert effects on ion channel function that are independent of the inability of these proteins to bind calcium. This should be taken into consideration when interpreting data that rely on these CaM mutants. 


\section{Conclusions}

CaM lobe mutants are capable of altering both the voltagedependent and kinetic properties of Cav1.2 channel activation in the absence of calcium. The Brugada syndrome mutation $\mathrm{A} 39 \mathrm{~V}$ reduces both $\mathrm{N}$-lobe $\mathrm{CDI}$ and augments Cav1.2 channel activation.

\section{Methods \\ cDNA constructs}

Wild type (WT) rat calcium channel subunit cDNAs encoding Cav1.2, Cav $\beta 2 \mathrm{a}$ and Cav $\alpha 2 \delta 1$ subunits, as well as the pMT2 vector were donated by Dr. Terry Snutch (University of British Columbia, Vancouver, BC). Wild type $\mathrm{CaM}$ and a CaM mutant with four mutated EF hands $\left(\mathrm{CaM}_{1234}\right)$ were a gift from Dr. John Adelman (Oregon Health Science University). GenBank ${ }^{\text {mat }}$ accession numbers, or origins of the clones used are as follows: Cav1.2 [M67515], Cavß2a [52], Cavo281 [AF286488], and CaM [NP_114175.1]. Creation of A39V-Cav1.2 [38] as well as $\mathrm{CaM}_{12}, \mathrm{CaM}_{34}$ and the Cav1.2 N-terminal GFP fusion protein $\mathrm{N}_{1}$-GFP have been previously described [23]. $\mathrm{N}_{1-\mathrm{EX}}{ }^{-}$ GFP was generated by PCR off of WT-Cav1.2 channel cDNA and cloned into N1-GFP (Clontech) using BamHI/ Xhol. Primers used to construct $\mathrm{N}_{1-\mathrm{EX}}$-GFP were: ATAT CTCGAGATGGTCAATGAAAACACG/TATAGGATCCC CGGGCGGCCGTGTGGCAGTTGTGC. All cDNAs were sequenced after cloning to verify fidelity.

\section{Tissue culture and transient transfection of tsA-201 cells}

Human embryonic kidney tsA-201 cells were cultured and transiently transfected using the calcium phosphate method as described previously [53]. For immunoblotting 3 ug of each cDNA was transfected per $10 \mathrm{~cm}$ plate. For electrophysiology experiments 6 ug of each alpha subunit and 3ug of $\operatorname{Cav} \beta 2 a$ and $C a v \alpha 2 \delta 1$ subunits were transfected per $10 \mathrm{~cm}$ plate. In addition, $125 \mathrm{ng}$ of GFP was included in each electrophysiology transfection to identify transfected cells. For western blot experiments, cells were grown at $37^{\circ} \mathrm{C}$ for $48 \mathrm{~h}$ ( $75-85 \%$ confluence), while cells for electrophysiology were kept to low confluence and were grown for 72 hours at $28^{\circ} \mathrm{C}$.

\section{Immunoblots and CaM pull-down assays}

Cultured tsA-201 cells were transiently transfected as described above with cDNAs for immunoprecipitation/ pull-down assays and were lysed with a modified RIPA buffer (in mM; 50 Tris, $130 \mathrm{NaCl}, 0.2 \%$ triton X-100, $0.2 \% \mathrm{NP}-40,5$ EGTA, or $\left.0.5 \mathrm{Ca}^{2+}, \mathrm{pH} 7.4\right)$. Lysis was carried out on ice for $15 \mathrm{~min}$ after which cells were centrifuged at 13,000 rpm for $5 \mathrm{~min}$ at $4^{\circ} \mathrm{C}$. Supernatants were transferred to new tubes and solubilized proteins were mixed with CaM Sepharose 4B beads (GE Healthcare Life Sciences) for pull-down assays overnight while tumbling at $4^{\circ} \mathrm{C}$. Pulldowns were washed three times with either $0.5 \mathrm{mM} \mathrm{Ca}^{2+}$, or $5 \mathrm{mM}$ EGTA lysis buffer, eluted with 2X Laemmli sample buffer and incubated at $96^{\circ} \mathrm{C}$ for $10 \mathrm{~min}$. Eluted samples were loaded on the appropriate percentage Tris-glycine gel and resolved using SDS-PAGE. Samples were transferred to $0.45 \mu \mathrm{m}$ PDVF membranes (Millipore) and immunoblot performed using 1/1000 anti-GFP (Santa-Cruz-8334). GE-Healthcare horseradish peroxidase-linked secondary antibodies (rabbit) was used at 1/5000 dilution. Total inputs were taken from whole cell samples and represented $2.5 \%$ of total protein.

\section{Voltage-clamp recordings}

Glass cover slips carrying cells WT or mutant Cav1.2 channels were transferred to a $1.5 \mathrm{ml}$ recording chamber and external recording solution consisting of $20 \mathrm{mM}$ $\mathrm{BaCl}_{2}$ or $20 \mathrm{mM} \mathrm{CaCl}, 1 \mathrm{mM} \mathrm{MgCl}, 10 \mathrm{mM}$ HEPES, $10 \mathrm{mM}$ Glucose and $136 \mathrm{mM} \mathrm{CsCl}$ (pH 7.4 adjusted with $\mathrm{CsOH}$ ) was perfused. Micro-electrode patch pipettes were pulled and polished using a DMZ- Universal Puller (Zeitz Instruments $\mathrm{GmbH}$ ) to a typical resistance of 3-5 $\mathrm{M} \Omega$. Low calcium buffering internal pipette solution consisted of $141 \mathrm{mM} \mathrm{CsCH} \mathrm{SO}_{3}, 0.5 \mathrm{mM}$ EGTA, $4 \mathrm{mM}$ $\mathrm{MgCl}_{2}$ and $10 \mathrm{mM}$ HEPES (pH 7.2 adjusted with $\mathrm{CsOH}$ ). High calcium buffering internal solution was prepared in the same way however less $\mathrm{CsCH}_{3} \mathrm{SO}_{3}(131 \mathrm{mM})$ was used to offset the increase in calcium buffer concentration of $10 \mathrm{mM}$ BAPTA. Added daily to internal solution was $5 \mathrm{mM}$ Di-Tris-Creatine Phosphate, $2 \mathrm{mM}$ Tris-ATP and $0.5 \mathrm{mM} \mathrm{Na}-\mathrm{GTP}$.

Whole cell patch clamp recordings were performed in voltage-clamp mode using an Axopatch 200B amplifier (Axon Instruments) linked to a personal computer with pCLAMP software version 9.2. Series resistance was compensated by $85 \%$, leak currents were negligible, and the data were filtered at $5 \mathrm{kHz}$. Individual GFP expressing cells were held at $-100 \mathrm{mV}$ and pulsed in $10 \mathrm{mV}$ increments from -60 to $+60 \mathrm{mV}$, for a period of 1 second. Individual pulses were separated by $15 \mathrm{~s}$ to enable full channel recovery. Only those cells whose whole cell current voltage relationships could be fit with the modified Boltzmann equation, $\mathrm{I}=\left(1 /\left(1+\exp ^{(-(\mathrm{Va}-\mathrm{V}) / \mathrm{S}))}\right) *\left(\mathrm{~V}-\mathrm{E}_{\mathrm{rev}}\right){ }^{* *} \mathrm{G}_{\text {max }}\right.$, where 'I' is current, ' $V_{a}$ ' is half-activation potential, ' $V$ ' is membrane potential, ' $E_{\text {rev }}$ ' is reversal potential, $S$ is the slope factor, and ' $G_{\max }$ ' is slope conductance, were used for determination of voltage-dependent properties. IV curves displayed in Figure 4 are ensemble fits, and because of variance in the data, not all conditions plotted reach a normalized value of -1 . Determination of Va was always determined by fitting individual whole cell current-voltage relationships, rather than using the ensemble fits.

For CDI experiments only cells with $>80 \mathrm{pA}$ of $\mathrm{Ba}^{2+}$ current proceeded to recordings in $\mathrm{Ca}^{2+}$. In order to quantify CDI we used a previously described method of paired analysis [21]. In this method the fraction of current 
remaining at $300 \mathrm{~ms}(\mathrm{r} 300)$ in $\mathrm{Ca}^{2+}$ is subtracted from the current fraction remaining at $300 \mathrm{~ms}$ in $\mathrm{Ba}^{2+}$. The difference obtained between the two charge carriers represents additional inactivation promoted by $\mathrm{Ca}^{2+}\left(\mathrm{f}_{300}\right)$, or rather CDI. Because $\mathrm{Ca}^{2+}$ conductance in the solutions used was maximal at $10 \mathrm{mV}$, the -100 to $10 \mathrm{mV}$ (1 sec) pulse was used for determining degree of CDI.

\section{Data analysis}

All electrophysiological data were analyzed using Clampfit version 10.2 (Axon Instruments) and plotted in Origin 9 (Origin Lab Corporation). Statistical analyses for both biochemical and electrophysiological data were carried out using Origin 9. All sample means are reported as +/-SEM. Statistically significant differences between means were assessed using student's $t$-test, or one-way ANOVA at the 95\% confidence level (followed by Tukey's test), as appropriate.

\section{Ethical standards}

All experiments performed in this manuscript comply with the laws of Canada.

\section{Abbreviations \\ CaM: Calmodulin; CDF: Calcium dependent facilitation; CDI: Calcium dependent inactivation; VGCC: Voltage gated calcium channel; $\mathrm{Ca}^{2}$ +/CaM: Calcium/calmodulin; VDA: Voltage dependent activation; WT- Cav1.2: Wild type Cav1.2; VDI: Voltage dependent inactivation; IV: Current voltage; Va: Half activation potential.}

\section{Competing interests}

The authors declare that they have no competing interests.

\section{Authors' contributions}

All authors were involved in the design of the study. BAS designed and carried out electrophysiology experiments, and drafted the manuscript. IAS designed and conducted biochemistry experiments. GWZ directed the study and edited the manuscript. All authors read and approved the final manuscript.

\section{Acknowledgements}

This work was supported by a grant from the Natural Sciences and Engineering Research Council. BAS is supported by a studentship from Alberta Innovates-Health Solutions (AI-HS). IAS is supported by a postdoctoral fellowship from Mitacs Elevate. GWZ is an AI-HS Scientist and a Canada Research Chair.

Received: 4 April 2014 Accepted: 23 April 2014

Published: 28 April 2014

\section{References}

1. Catterall WA: Structure and regulation of voltage-gated $\mathrm{Ca} 2+$ channels. Annu Rev Cell Dev Biol 2000, 16:521-551.

2. Simms BA, Zamponi GW: Neuronal voltage-gated calcium channels: structure, function and dysfunction. Neuron 2014, 82:24-45.

3. Jeon D, Kim S, Chetana M, Jo D, Ruley HE, Lin SY, Rabah D, Kinet JP, Shin HS: Observational fear learning involves affective pain system and Cav1.2 Ca2+ channels in ACC. Nat Neurosci 2010, 13(4):482-488.

4. Langwieser N, Christel CJ, Kleppisch T, Hofmann F, Wotjak CT, Moosmang S: Homeostatic switch in hebbian plasticity and fear learning after sustained loss of Cav1.2 calcium channels. J Neurosci 2012, 30(25):8367-8375.

5. Shaw RM, Colecraft HM: L-type calcium channel targeting and local signalling in cardiac myocytes. Cardiovasc Res 2013, 98(2):177-186.

6. Harvey RD:, Hell JW: CaV1.2 signaling complexes in the heart. J Mol Cell Cardiol 2013, 58:143-152
7. Weiss S, Oz S, Benmocha A, Dascal N: Regulation of cardiac L-type $\mathrm{Ca}(2)(+)$ channel CaV1.2 via the beta-adrenergic-cAMP-protein kinase A pathway: old dogmas, advances, and new uncertainties. Circ Res 2013, 113(5):617-631.

8. Seisenberger C, Specht V, Welling A, Platzer J, Pfeifer A, Kuhbandner S, Striessnig J, Klugbauer N, Feil R, Hofmann F: Functional embryonic cardiomyocytes after disruption of the L-type alpha1C (Cav1.2) calcium channel gene in the mouse. J Biol Chem 2000, 275(50):39193-39199.

9. Antzelevitch C, Pollevick GD, Cordeiro JM, Casis O, Sanquinetti MC, Aizawa Y, Guerchicoff A, Pfeiffer R, Oliva A, Wollnik B, Gelber P, Bonaros EP Jr, Burashnikov E, Wu Y, Sargent JD, Schickel S, Oberheiden R, Bhatia A, Hsu LF, Haissaguerre M, Schimpf R, Borggrefe M, Wolpert C: Loss-of-function mutations in the cardiac calcium channel underlie a new clinical entity characterized by ST-segment elevation, short QT intervals, and sudden cardiac death. Circulation 2007, 115(4):442-449.

10. Burashnikov E, Pfeiffer R, Barajas-Martinez H, Delpon E, Hu D, Desai M, Borggrefe M, Haissaguerre M, Kanter R, Pollevick GD, Guerchicoff A, Laino R, Marieb M, Nademanee K, Nam GB, Robles R, Schimpf R, Stapleton DD, Viskin S, Winters S, Wolpert C, Zimmern S, Veltmann C, Antzelevitch C: Mutations in the cardiac L-type calcium channel associated with inherited J-wave syndromes and sudden cardiac death. Heart Rhythm 2010, 7(12):1872-1882.

11. Brugada P, Brugada J: Right bundle branch block, persistent ST segment elevation and sudden cardiac death: a distinct clinical and electrocardiographic syndrome. A multicenter report. J Am Coll Cardiol 1992, 20(6):1391-1396.

12. Simms BA, Zamponi GW: Trafficking and stability of voltage-gated calcium channels. Cell Mol Life Sci 2012, 69(6):843-856.

13. Clapham DE: Calcium signaling. Cell 2007, 131(6):1047-1058.

14. Zuhlke RD, Pitt GS, Deisseroth K, Tsien RW, Reuter H: Calmodulin supports both inactivation and facilitation of L-type calcium channels. Nature 1999, 399(6732):159-162

15. Peterson BZ, DeMaria CD, Adelman JP, Yue DT: Calmodulin is the Ca2+ sensor for $\mathrm{Ca} 2+-$ dependent inactivation of L-type calcium channels. Neuron 1999, 22(3):549-558.

16. Qin N, Olcese R, Bransby M, Lin T, Birnbaumer L: Ca2 + -induced inhibition of the cardiac Ca2+ channel depends on calmodulin. Proc Natl Acad Sci U S A 1999, 96(5):2435-2438.

17. Peracchia C, Sotkis A, Wang XG, Peracchia LL, Persechini A: Calmodulin directly gates gap junction channels. J Bio/ Chem 2000, 275(34):26220-26224.

18. Xia XM, Fakler B, Rivard A, Wayman G, Johnson-Pais T, Keen JE, Ishii T, Hirschberg B, Bond CT, Lutsenko S, Maylie J, Adelman JP: Mechanism of calcium gating in small-conductance calcium-activated potassium channels. Nature 1998, 395(6701):503-507.

19. Moreau B, Straube S, Fisher RJ, Putney JW Jr, Parekh AB: Ca2 + -calmodulindependent facilitation and $\mathrm{Ca} 2+$ inactivation of $\mathrm{Ca} 2+$ release-activated Ca2+ channels. J Biol Chem 2005, 280(10):8776-8783.

20. Rey O, Young SH, Papazyan R, Shapiro MS, Rozengurt E: Requirement of the TRPC1 cation channel in the generation of transient Ca2+ oscillations by the calcium-sensing receptor. J Biol Chem 2006, 281(50):38730-38737.

21. de Maria CD, Soong TW, Alseikhan BA, Alvania RS, Yue DT: Calmodulin bifurcates the local Ca2+ signal that modulates P/Q-type Ca2+ channels. Nature 2001, 411(6836):484-489.

22. Dick IE, Tadross MR, Liang H, Tay LH, Yang W, Yue DT: A modular switch for spatial $\mathrm{Ca} 2+$ selectivity in the calmodulin regulation of $\mathrm{CaV}$ channels. Nature 2008, 451(7180):830-834

23. Simms BA, Souza IA, Zamponi GW: A novel calmodulin site in the Cav1.2 $\mathrm{N}$-terminus regulates calcium-dependent inactivation. Pflugers Arch 2013 In press.

24. Johny MB, Yang PS, Bazzazi H, Yue DT: Dynamic switching of calmodulin interactions underlies $\mathrm{Ca} 2+$ regulation of CaV1.3 channels. Nat Commun 2013, 4:1717.

25. Alseikhan BA, DeMaria CD, Colecraft HM, Yue DT: Engineered calmodulins reveal the unexpected eminence of $\mathrm{Ca} 2+$ channel inactivation in controlling heart excitation. Proc Natl Acad Sci U S A 2002, 99(26):17185-17190.

26. Hall DD, Dai S, Tseng PY, Malik Z, Nguyen M, Matt L, Schnizler K, Shephard A, Mohapatra DP, Tsuruta F, Dolmetsch RE, Christel CJ, Lee A, Burette A, Weinberg RJ, Hell JW: Competition between alpha-actinin and $\mathrm{Ca}(2)(+)-$ calmodulin controls surface retention of the L-type $\mathrm{Ca}(2)(+)$ channel $\mathrm{Ca}(\mathrm{V})$ 1.2. Neuron 2013, 78(3):483-497.

27. Zhang M, Tanaka T, Ikura M: Calcium-induced conformational transition revealed by the solution structure of apo calmodulin. Nat Struct Biol 1995, 2(9):758-767. 
28. Komeiji $Y$, Ueno $Y$, Uebayasi M: Molecular dynamics simulations revealed $\mathrm{Ca}(2+)$-dependent conformational change of calmodulin. FEBS Lett 2002, 521(1-3):133-139.

29. Finn BE, Evenas J, Drakenberg T, Waltho JP, Thulin E, Forsen S: Calciuminduced structural changes and domain autonomy in calmodulin. Nat Struct Biol 1995, 2(9):777-783.

30. Chou JJ, Li S, Klee CB, Bax A: Solution structure of Ca(2+)-calmodulin reveals flexible hand-like properties of its domains. Nat Struct Biol 2001, 8(11):990-997.

31. Wriggers W, Mehler E, Pitici F, Weinstein H, Schulten K: Structure and dynamics of calmodulin in solution. Biophys J 1998, 74(4):1622-1639.

32. Gariepy J, Mietzner TA, Schoolnik GK: Peptide antisera as sequencespecific probes of protein conformational transitions: calmodulin exhibits calcium-dependent changes in antigenicity. Proc Natl Acad Sci U S A 1986, 83(23):8888-8892.

33. Benmocha A, Almagor L, Oz S, Hirsch JA, Dascal N: Characterization of the calmodulin-binding site in the $\mathrm{N}$ terminus of CaV1.2. Channels (Austin) 2009, 3(5):337-342

34. Pitt GS, Zuhlke RD, Hudmon A, Schulman H, Reuter H, Tsien RW: Molecular basis of calmodulin tethering and $\mathrm{Ca} 2+-$ dependent inactivation of L-type Ca2+ channels. J Biol Chem 2001, 276(33):30794-30802.

35. Erickson MG, Alseikhan BA, Peterson BZ, Yue DT: Preassociation of calmodulin with voltage-gated $\mathrm{Ca}(2+)$ channels revealed by FRET in single living cells. Neuron 2001, 31(6):973-985.

36. Van Petegem F, Chatelain FC, Minor DL Jr: Insights into voltage-gated calcium channel regulation from the structure of the CaV1.2 IQ domain-Ca2+/calmodulin complex. Nat Struct Mol Biol 2005, 12(12):1108-1115.

37. Kim EY, Rumpf CH, Van Petegem F, Arant RJ, Findeisen F, Cooley ES, Isacoff EY, Minor DL Jr: Multiple C-terminal tail $\mathrm{Ca}(2+) / \mathrm{CaMs}$ regulate $\mathrm{Ca}(\mathrm{V}) 1.2$ function but do not mediate channel dimerization. EMBO J 2010, 29(23):3924-3938.

38. Simms BA, Zamponi GW: The Brugada syndrome mutation A39V does not affect surface expression of neuronal rat Cav1.2 channels. Mol Brain 2012, 5:9.

39. Peterson BZ, Lee JS, Mulle JG, Wang Y, de Leon M, Yue DT: Critical determinants of $\mathrm{Ca}(2+)$-dependent inactivation within an EF-hand motif of L-type $\mathrm{Ca}(2+)$ channels. Biophys J 2000, 78(4):1906-1920.

40. Bazzazi H, Ben Johny M, Adams PJ, Soong TW, Yue DT: Continuously tunable $\mathrm{Ca}(2+)$ regulation of RNA-edited CaV1.3 channels. Cell Rep 2013, 5(2):367-377.

41. Stea A, Tomlinson WJ, Soong TW, Bourinet E, Dubel SJ, Vincent SR, Snutch TP: Localization and functional properties of a rat brain alpha $1 \mathrm{~A}$ calcium channel reflect similarities to neuronal Q- and P-type channels. Proc Nat Acad Sci U S A 1994, 91(22):10576-10580.

42. Stotz SC, Zamponi GW: Structural determinants of fast inactivation of high voltage-activated $\mathrm{Ca}(2+)$ channels. Trends Neurosci 2001, 24(3):176-181.

43. Hurley $\mathrm{JH}$, Cahill AL, Currie KP, Fox AP: The role of dynamic palmitoylation in Ca2+ channel inactivation. Proc Natl Acad Sci U S A 2000, 97(16):9293-9298.

44. Liang H, DeMaria CD, Erickson MG, Mori MX, Alseikhan BA, Yue DT: Unified mechanisms of $\mathrm{Ca} 2+$ regulation across the $\mathrm{Ca} 2+$ channel family. Neuron 2003, 39(6):951-960.

45. Antzelevitch C, Brugada P, Borggrefe M, Brugada J, Brugada R, Corrado D, Gussak I, LeMarec H, Nademanee K, Perez Riera AR, Shimizu W, Schulze-Bahr E, Tan H, Wilde A: Brugada syndrome: report of the second consensus conference. Heart Rhythm 2005, 2(4):429-440.

46. Agler HL, Evans J, Tay LH, Anderson MJ, Colecraft HM, Yue DT: G proteingated inhibitory module of N-type (ca(v)2.2) ca2+ channels. Neuron 2005, 46(6):891-904

47. de Leon M, Wang $Y$, Jones L, Perez-Reyes E, Wei X, Soong TW, Snutch TP, Yue DT: Essential $\mathrm{Ca}(2+)$-binding motif for $\mathrm{Ca}(2+)$-sensitive inactivation of L-type Ca2+ channels. Science 1995, 270(5241):1502-1506.

48. Zhou J, Olcese R, Qin N, Noceti F, Birnbaumer L, Stefani E: Feedback inhibition of $\mathrm{Ca} 2+$ channels by $\mathrm{Ca} 2+$ depends on a short sequence of the $\mathrm{C}$ terminus that does not include the $\mathrm{Ca} 2+-$ binding function of a motif with similarity to Ca2+ - binding domains. Proc Natl Acad Sci U S A 1997, 94(6):2301-2305.

49. Kim J, Ghosh S, Nunziato DA, Pitt GS: Identification of the components controlling inactivation of voltage-gated Ca2+ channels. Neuron 2004, 41(5):745-754.
50. Brunet $\mathrm{S}$, Scheuer T, Klevit R, Catterall WA: Modulation of CaV1.2 channels by $\mathrm{Mg} 2+$ acting at an EF-hand motif in the $\mathrm{COOH}$-terminal domain. J Gen Physiol 2005, 126(4):311-323.

51. Brunet $\mathrm{S}$, Scheuer T, Catterall WA: Cooperative regulation of $\mathrm{Ca}(\mathrm{v}) 1.2$ channels by intracellular $\mathrm{Mg}(2+)$, the proximal C-terminal EF-hand, and the distal C-terminal domain. J Gen Physiol 2009, 134(2):81-94.

52. Perez-Reyes E, Castellano A, Kim HS, Bertrand P, Baggstrom E, Lacerda AE, Wei XY, Birnbaumer L: Cloning and expression of a cardiac/brain beta subunit of the L-type calcium channel. J Biol Chem 1992, 267(3):1792-1797.

53. Hamid J, Nelson D, Spaetgens R, Dubel SJ, Snutch TP, Zamponi GW: Identification of an integration center for cross-talk between protein kinase $\mathrm{C}$ and $\mathrm{G}$ protein modulation of $\mathrm{N}$-type calcium channels. J Biol Chem 1999, 274(10):6195-6202.

doi:10.1186/1756-6606-7-34

Cite this article as: Simms et al:: Effect of the Brugada syndrome mutation A39V on calmodulin regulation of Cav1.2 channels. Molecular Brain 2014 7:34

\section{Submit your next manuscript to BioMed Central and take full advantage of:}

- Convenient online submission

- Thorough peer review

- No space constraints or color figure charges

- Immediate publication on acceptance

- Inclusion in PubMed, CAS, Scopus and Google Scholar

- Research which is freely available for redistribution 